\title{
Lo bello y lo bueno en el discurso oral y escrito: Implicaciones pedagógicas del Fedro de Platón*
}

\section{The beautiful and the good in oral and written speech: Pedagogic implications of Platón Phaedrus}

\author{
Carlos Adolfo Rengifo Castañeda ** \\ Diana Carolina Cañaveral *** \\ Mario Alberto Álvarez López **** \\ Luz Adriana Bernal López *****
}

\begin{abstract}
**Profesional en Filosofía de la Universidad del Quindío. Especialista en Pedagogía y Docencia Universitaria de la Universidad La Gran Colombia. Magíster en Filosofía de la Universidad del Valle y Doctorando en Filosofía de la Universidad Pontifica Bolivariana de Medellín. integrante de los grupos de investigación Paideia de la UGCA y Educación: Desarrollo Humano de la USB de Cali. Docente de la Universidad San Buenaventura de Cali. e-mail: careca1106@ gmail.com y carengifo1@usbcali.educo.

***Abogada de la Universidad La Gran Colombia Seccional Armenia, (E) Maestría en Derecho Público en la misma Universidad. Docente investigadora, líder del Grupo de Investigación de Derecho Público de la Universidad la Gran Colombia Seccional Armenia. E-mail: canaverallondiana@miugca.edu.co.

****Economista de la Universidad La Gran Colombia, Especialista en Gestión y Planificación Urbana y Regional de la Escuela Superior de Administración Pública, Especialista en Docencia Universitaria U.G.C., Magister en Educación de la Universidad de Manizales, Doctor en Educación Social de la Universidad de Granada España. Doctor en Ciencias de la Educación de la Universidad Tecnológica de Pereira. Investigador del Grupo de Investigación Educación y Desarrollo Humano. Email: marioalbertoal@gmail.com y maalvarez2@usbcali.edu.co.
\end{abstract}

*****Licenciada en Biología y Educación Ambiental de la Universidad del Quindío, Profesional en Gestión de Recursos Naturales, docente universitaria e-mail: luzadrib29@gmail.com.

Cómo citar: Rengifo, C.A; Cañaveral, D.C; Álvarez, M.A \& Bernal, L.A. (2016) Lo bello y lo bueno en el discurso oral y escrito: Implicaciones pedagógicas del fedro de Platon.Sophia 12(1):127-137.

\section{Resumen}

Este artículo pretende comprender los argumentos expuestos por Platón en el diálogo del Fedro, que permiten identificar algunas de las implicaciones de su propuesta en el discurso tanto oral como escrito y su incidencia en el pensamiento contemporáneo. Lo anterior, mediante un ejercicio de revisión bibliográfica (apelando a fuentes primarias y secundarias), que posibilitan el reconocimiento de que, finalmente, solo quien proceda del modo señalado por este discípulo de Sócrates en el texto del Fedro, podrá ser llamado "filósofo, amante de la sabiduría".

Palabras Clave: Filosofía, pluralismo, oratoria, discurso, pedagogía, fedro. 


\begin{abstract}
The purpose of this article is to understand Plato's arguments in dialogue of the Phaedrus, which lead to identify some implications of his proposal, both in oral and written speech, and their impact on contemporary thought. The above, through a bibliographic review, (appealing to primary and secondary sources), which make it possible to recognize that, finally, only the one proceeding as stated by this Socrates' disciple in the text of the Phaedrus, may be named as "philosopher, lover of wisdom".
\end{abstract}

Keywords: Philosophy, pluralism, public speaking, speech, pedagogy

\section{Introducción}

Sóc. - Antes de que alguien vea la verdad de aquello sobre lo que habla o escribe, y llegue a ser capaz de definir cada cosa en sí $y$, definiéndola, sepa también dividirla en sus especies hasta lo indivisible, y por este procedimiento se haya llegado a conocer a fondo la naturaleza del alma, descubriendo la clase de palabras adecuadas a la naturaleza de cada una,

y establezca y adorne el discurso de manera que dé al alma compleja discursos complejos y multisonoros, y simples a la simple, no será posible que se llegue a manejar con arte el género de los discursos, en la medida en que su naturaleza lo permita, ni para enseñarlos ni para persuadir, según nos hace suponer todo lo que anteriormente hemos dicho.

Pretender conjeturar acerca de uno de los diálogos de este filosofo clásico de la Grecia antigua, invita al lector a aproximarse a la riqueza de su pensamiento reconociendo, en la filosofía platónica, aportes significativos a los problemas epistemológicos, antropológicos, ontológicos, teológicos, políticos y pedagógicos -entre otros- que, aún con el pasar de los siglos, continúan presentes en el pensamiento contemporáneo.
Con el propósito de situar el diálogo del $\mathrm{Fedro}^{1}$ en su contexto cronológico en relación con la obra platónica, Emilio Lledó Iñigo afirma, en la introducción que hace a la edición de Gredos (1988), que este escrito ha sido objeto de múltiples y muy variadas contradicciones respecto a su fecha de confección:

«Dicen que la primera obra que escribió fue el Fedro», cuenta también Diógenes Laercio (11I 38). Tal vez el adjetivo «juvenil» (meirakiodes) que transmite, en el mismo pasaje, Diógenes, a propósito del «problema» que aborda el Fedro, podría haber llevado a Schleiermacher a defender, ya en el siglo XIX, la tesis de que era, efectivamente, el Fedro, si no el primero, uno de los primeros escritos de Platón en el que se hacía una especie de programa de lo que iba a desarrollarse posteriormente. (Lledó, 1988: 292).

Asimismo, en el libro de la Paideia de Werner Jaeger, afirma que al parecer este diálogo puede ser apreciado como un trabajo primitivo de Platón y que, a su vez, refleja el programa mismo de la Academia platónica, además fue considerado por mucho tiempo:

[...] como el punto natural de partida para comprender los últimos fines a que se encaminaba la obra de Platón como escritor y sus métodos educativos. Brindaba el compendio más breve de las ideas Platónicas acerca de la relación entre el escrito, la palabra hablada y el pensamiento y era, por tanto, el pórtico por el que todos entraban al templo de la filosofía de Platón. (Jaeger, 2001: 982).

\footnotetext{
1.Según Emilio Lledó: "El personaje que da nombre al diálogo sí es un personaje histórico. Era hijo del ateniense Pítocles, amigo de Demóstenes y, posteriormente, de Esquines. Fedro aparece también en el Protágoras (3l5c) rodeando al sofista Hipias que disertaba sobre los meteoros. En el Banquete, es Fedro el primero que iniciará su discurso sobre Eros (178a-180b)". (Platón, Diálogo III (Fedón, Banquete y Fedro), 1988, p. 293).
} 
Sin embargo, en la misma edición de Gredos mencionada, se sugiere que el Fedro, junto al Fedón, el Banquete y la República, forman parte del grupo de diálogos considerados de la madurez de su autor, ubicándolo entre los últimos escritos y precedido por la República. Con todo, a pesar de la controversia que suscita la ubicación cronológica del diálogo, en lo que coinciden varios autores $-\mathrm{y}$ aparece claro en este artículo-, es en la importancia de este: "Divided into a prologue, three speeches on erôs, love (q.v.) and a discussion of good and bad speaking and writing" (Gonzalez, Nails, \& Tarrant, 2012: 78), diálogo este en el que, a diferencia del Banquete: "Not the positive, but the negative sides of erôs are highlighted in the first two speeches" (Gonzalez, Nails, \& Tarrant, 2012: 79), con lo que se posibilita, en buena medida, un acercamiento del lector a la comprensión del pensamiento platónico.

Ahora bien, antes de desarrollar el tema central de este artículo, y teniendo en cuenta que dentro del diálogo objeto del mismo se halla contenido -entre otros- el mito del carro alado, una de las alegorías más destacadas del pensamiento platónico, es necesario tratar de comprender de manera un tanto sucinta, pero clara, qué papel juega el mito en el pensamiento de Platón. En primer lugar, se debe reconocer, en un mito platónico: "Un tejido delicado que puede destruirse mediante cualquier intento de separar sus hilos entretejidos" (Guthrie, 1990: 350), pues conforman una inescindible relación o mixtura de conceptos y categorías de orden epistemológico, ontológico, antropológico, pedagógico, ético y político, entre otros, que dan cuenta de la doctrina filosófica de Platón.

En segundo lugar, debe comprenderse cuál era precisamente el propósito que el mito tenía en aquellos tiempos, pues: "En la época de Platón no se podía trazar una línea firme entre mito (o creencia religiosa) y lo que era considerado como un hecho científico" (Guthrie, 1990: 349), razón por la cual debe evitarse incurrir en esa dualidad entre la verdad y la mentira a la hora de comprender el mito, con el que, en últimas, Platón intenta abordar la comprensión de cuestiones que no pueden ser probablemente comprendidas meramente a través de la discusión dialéctica, según lo explica el autor citado al referirse al carácter del mito platónico:
La verdad no radica en una interpretación literal de los detalles del relato, sino en la lección que transmite al mostrar que la ética socrática no es sólo moralmente superior [...], sino que conduce finalmente a una mayor felicidad para el individuo. Es una extensión del argumento con la que éste se adentra en regiones que están más allá del alcance de la discusión dialéctica (Guthrie, 1990: 298).

Sumado a lo anterior, cada mito debe ser leído, comprendido e interpretado en el contexto del diálogo, pues cada coloquio proporciona las herramientas pedagógicas necesarias para comprenderlo, sus contenidos racionales y lo que quiere decir, lo que hace de estos mitos un instrumento del conocimiento de gran alcance y relevancia al interior de la filosofía de Platón, pues se presentan no solo como simples: "Historias que se cuentan a los niños, de contenido ficticio" (Guthrie, 1990: 467), sino que, además: "En el caso de ser mitos buenos, ilustran las verdades morales, o alegorías transparentes" (Guthrie, 1990: 467). Así, el mito se constituye en un importante recurso pedagógico, didáctico y conceptual para la comprensión de distintas cuestiones como las morales, cuyo abordaje sobrepasa la exposición de simples contenidos teóricos. Adicional a esto, se debe decir: "En la República y en el Fedro, el mito gana independencia en su contenido; este no debe explicar, sino revelar" (Görgemanns, 2010: 63), tratándose, con esto, de un discurso de la revelación.

\section{Desarrollo}

Respecto al objeto particular de este escrito, relativo a lo bello y lo bueno dentro de los discursos orales y escritos (bien sean académicos, políticos o de tribunales), vistos a la luz del diálogo del Fedro de Platón y sus posibles implicaciones en la contemporaneidad, se puede afirmar que este mismo es, en primera medida, una invitación a "salir de Atenas", a "salir de las murallas" en las que el hombre se encuentra encerrado, y dentro de las que se cuentan algunas de las corrientes del pensamiento contemporáneo:

Sócrates. - Mi querido Fedro, ¿adónde andas ahora y de dónde vienes?

Fedro. - De con Lisias, Sócrates, el de Céfalo, y me voy fuera de las murallas, a dar una vuelta. Porque me he entretenido allí mucho tiempo, 
sentado desde temprano. Persuadido, además, por Acúmeno, compañero tuyo y mío, voy a dar un paseo por los caminos, ya que, afirma, es más descansado que andar por los lugares públicos

(...) Sócrates. - ¿Y de qué habéis tratado? Porque seguro que Lisias os regaló con su palabra

Fedro. - Lo sabrás, si tienes un rato para

escucharme mientras paseamos.

(Platón, 1988: 309-310) (227a-b).

Se advierte, así, un anhelo por encontrar un lugar apropiado que promueva nuevas experiencias frente al conocimiento. En este sentido, Sócrates sugiere: "Desviémonos por aquí y vayamos por la orilla del Itiso, y allí, donde mejor nos parezca, nos sentaremos tranquilamente" (229a), pues es en la tranquilidad del alma, en su encuentro con el mundo sensible, en donde se posibilita el reconocimiento de la realidad que habita en el mundo de las ideas y, con ella, la verdad, dejando atrás a la ciudad y la institucionalización del conocimiento, y facilitando, de este modo, el aprendizaje de la filosofía como un asunto de carácter personal, mediado por el diálogo a través del cual la realidad le acontece al hombre.

En estas primeras palabras con las que inicia el Fedro se evidencia la importancia del diálogo en el pensamiento platónico, cuya forma literaria recibe una interpretación de carácter didáctico por parte de Görgemanns, según la cual:

Los pensamientos filosóficos no podrían ser transmitidos por medio de un libro (como hace claro Platón en el Fedro), sino solamente por medio de conversaciones didácticas. Sin embargo, las desventajas de la escritura podrían superarse si el libro imitase una conversación didáctica. Ésta tendría como finalidad 'que el lector sea llevado o a la propia creación interna de la idea que Platón tiene en mente o a un pensamiento determinado después de no haber encontrado y no haber entendido nada. (Görgemanns, 2010: 51).

El diálogo, en consecuencia, facilita el ejercicio filosófico al no transmitir una doctrina determinada y permitirle sí, al interlocutor/lector, llegar a una conclusión pero a partir de sus propias reflexiones, las cuales fueron posibilitadas por el mensaje mismo que contiene el diálogo. Respecto a este mensaje, Alexandre Koyre afirma:
Este mensaje -según se nos dice- es, desde luego, filosófico, y los diálogos entrañan una enseñanza; pero ésta -se nos asegura de nuevo- no es doctrinal, sino una lección de método. Sócrates nos enseña el uso y el valor de las definiciones precisas de los conceptos empleados en los debates, y la imposibilidad de llegar a conseguirlas si no se procede antes a una revisión crítica de las nociones tradicionales, de las concepciones «vulgares» admitidas e incorporadas en el lenguaje (Koyre, 1966: 25).

De este modo, el diálogo como método aprueba el desplazamiento que se da del mundo de lo sensible hacia el mundo de las ideas, filosofando y generando estrategias tanto para el pensamiento como para el diálogo mismo, para el decir que se posibilita mediante otros decires y que, de esta manera, alimenta al logos-logos.

Siguiendo a Martha Nussbaum, existe un último aspecto contextual de gran importancia que se debe agregar en relación con Sócrates:

El Sócrates histórico nunca escribió. No lo hizo (si creemos la versión platónica) porque pensaba que el verdadero valor de la filosofía reside en la interacción de maestro y discípulo, cuando el primero guía al segundo interrogándole (a veces con suavidad otras con rudeza, según el carácter y la resistencia del interlocutor) para hacerlo más consciente de sus propias opiniones y de las relaciones entre ellas. (Nussbaum, 2004:181).

Esta explicación, para ejemplificar lo que se decía sobre la pretensión del mito, apare más clara tras la lectura del mito de Theuth y Thamus, en el que el rey egipcio rechaza el arte de la escritura que le ofrece el dios Thamus:

¡Oh artificiosísimo Theuth! A unos les es dado crear arte, a otros juzgar qué de daño o provecho aporta para los que pretenden hacer uso de él. Y ahora tú, precisamente, padre que eres de las letras, por apego a ellas, les atribuyes poderes contrarios a los que tienen. Porque es olvido lo que producirán en las almas de quienes las aprendan, al descuidar la memoria, ya que, fiándose de lo escrito, llegarán al recuerdo desde fuera, a través de caracteres ajenos, no desde dentro, desde ellos mismos y por sí mismos (Platón, 1988: 403).

Así concebida entonces, se entiende una dialéctica filosófica que enseña con arte, que muestra con 
precisión la verdad que descansa en la realidad sobre la que versa el discurso, ese que en palabras de Sócrates: "Se escribe con ciencia en el alma del que aprende; capaz de defenderse a sí mismo, y sabiendo con quiénes hablar y ante quiénes callarse (Platón, 1988: 405). Al respecto afirma Nussbaum:

La verdadera filosofía, tal como la entiende Sócrates, es la búsqueda comprometida de la verdad, en la cual no solo importa la aceptación de ciertas conclusiones, sino el seguimiento de un determinado camino que conduce a ellas, no sólo alcanzar el contenido correcto, sino hacerlo mediante el saber y el saber de sí verdaderos. (Nussbaum, 2004: 182).

Pero ese discurso, que se posibilita en el ejercicio dialéctico, no se olvida de asombrarse y maravillarse ante las cosas, por cotidianas que parezcan, como bien se advierte de las manifestaciones de Sócrates:

¡Por Hera! Hermoso rincón, con este plátano tan frondoso y elevado. Y no puede ser más agradable la altura y la sombra de este sauzgatillo, que, como además, está en plena flor, seguro que es de él este perfume que inunda el ambiente. Bajo el plátano mana también una fuente deliciosa, de fresquísima agua, como me lo están atestiguando los pies. Por las estatuas y figuras, parece ser un santuario de ninfas, o de Aqueloo. Y si es esto lo que buscas, no puede ser más suave y amable la brisa de este lugar. Sabe a verano, además, este sonoro coro de cigarras. Con todo, lo más delicioso es este césped que, en suave pendiente, parece destinado a ofrecer una almohada a la cabeza placenteramente reclinada. ¡En qué buen guía de forasteros te has convertido, querido Fedro! (Platón, 1988:316) (230b, e).

Se decía, algunos párrafos atrás, que el diálogo iniciaba con una invitación -hecha por Fedro a Sócrates- a salir de Atenas, con el fin de posibilitar un ejercicio filosófico que no se viera distraído o condicionado por las murallas que predeterminan el pensamiento. Ese ejercicio, propuesto así en este diálogo será, por esto, tanto del hombre en cuanto al cultivo de su alma, como epistemológico, pues tiende a la justificación racional de las creencias acerca de la naturaleza, del hombre y de lo otro, y es en esto, precisamente, en donde radica la importancia actual de aceptar esa invitación, de salir efectivamente de los diques que moderan y mesuran la reflexión y el pensamiento.
Se pretende, con esto, el abandono de aquellos discursos que, de una parte, carecen de razones necesarias -y sobre todo suficientes- para justificar lo que en ellos se afirma como verdadero, deviniendo, por tal motivo, en charlatanería; y de otra parte, discursos que solo logran afectar en el interlocutor sus emociones mediante la apariencia y la persuasión, propias de un tipo de retórica que desconoce intereses de orden epistemológico -necesariamente presentes en aquellos individuos inquietos por algún tipo de conocimiento debidamente justificado-, discursos estos -como el de Lisias, por ejemplo-que terminan entonces por negar una educación propiamente filosófica, en la medida en que niegan la necesidad del método dialéctico como herramienta para llegar a la verdad de lo que se habla, y posibilitando una retórica afincada en simples verosimilitudes (eikós).

Lo anterior no implica que la retórica, como forma de discurso, sea censurada en su totalidad por Platón. Por el contrario, este hace una diferencia entre dos posibles formas retóricas: la sofista -como la que objeta en el discurso de Lisias- y la filosófica, a la que se llega a través de la dialéctica, y a la que -en cierto modo- invita el Fedro a través del ejercicio filosófico de reflexión y búsqueda del Bien, como lo afirma Mary McCoy :

While sophistic rhetoric seeks only to gratify its audience, philosophical rhetoric seeks to lead the soul to further inquiry and reflection, and to the good itself. By including both advocates and critics of rhetoric in the dialogues, Plato encourages his readers to seek to understand more deeply the question of how one ought to live one's life (McCoy, 2012, p. 243).

Ahora bien, considerando desde la contemporaneidad este asunto, se podría formular un interrogante en relación con los procesos educativos y políticos que actualmente rigen las esferas académicas y político-sociales: ¿Se está transitando por el camino del discurso de Lisias y su mala retórica, en la que se argumenta a partir de premisas falsas de manera intencionada e ignorando la verdad? De ser así, dichos procesos estarían viciados por esa técnica que repudia Sócrates en Lisias y en virtud de la cual, este sofista recibe el epíteto de "logógrafo" (logografo $\varsigma^{2}$

2. Lisias había sido "censurado por un político por su profesión de componedor de discursos. A ello responde Sócrates que el mero hecho en sí de escribir no es nada reprochable, sino el hacerlo mal, tomando la palabra lo- 
- componedor de discursos), instalándose, además, como objeto de problematización en el diálogo del Fedro.

Esta tendencia escritural de Lisias, insigne representante de la retórica de la época, condujo a Sócrates a elaborar un primer discurso claramente afectado por esta condición de carácter falaz y cargada de persuasión. Tal acontecimiento compelió al maestro Sócrates, como solo la verdad puede hacerlo, a un segundo discurso, construido este a modo de retractación pública o "palinodia-palinwdia", por haber aceptado continuar con el juego de Lisias.

Esta "palinodia" -provocada, según Luis Gil (1983) en su traducción del Fedro, por una misteriosa llamada de sus demonios- es, en esencia, la invitación que hace Sócrates a decir la verdad donde antes se dijo, de modo intencional, la falsedad. Palinodia esta a la que llega Sócrates luego de descubrirse el rostro, pues se lo había cubierto para recorrer el camino de Lisias, caracterizado por una clara indiferencia por la verdad respecto al Amor:

[...] de repente, [Sócrates] cae en la cuenta de que su alma se ha manchado por las impuras palabras de su boca. Ha injuriado a un dios, al dios Eros, el cual como relatan las leyendas mitológicas, es hijo de Afrodita $\mathrm{y}$, por ello merece elogio y no la critica que sobre él han vertido los dos discursos pronunciados. (García, 2007:112).

Luego, y posterior a la purificación realizada con "temor reverencial", Sócrates se retracta, de una parte, por haber incurrido en errores en su razonamiento, y de la otra, por haber pecado contra el dios Eros- eros, producto del hechizo del cual fue víctima. Esta es la razón de sus palabras, al afirmar:

Yo voy a intentar ser más sabio que ellos, al menos, en esto. Por tanto, antes de que me sobrevenga alguna desgracia por haber maldicho del Amor le voy a ofrecer una palinodia, a cara descubierta, y no tapado, como antes, por vergüenza (Platón, 1988: 339) (243b).

De aquí la importancia de actualizar, al interior de $\underline{\text { este escrito, la pregunta formulada, en los siguientes }}$ gographia no en su sentido habitual, sino etimológico de escribir discursos sobre cualquier materia" (Platón, El Banquete, Fedón, Fedro, 1983, p. 268), Traducción de Luis Gil. términos ¿Cuántas proposiciones y/o argumentos, construidos al interior de las murallas del escenario educativo, político y académico, reclaman de una palinodia en sus oradores, es decir, requieren de evidentes retractaciones públicas, por situarse en el camino intencional de la mera persuasión, apariencia y aprobación de las mayorías, independientemente de la verdad que se halla en ellos?

\section{Estructura del diálogo}

En lo que concierne a la estructura del diálogo del $\mathrm{Fedro}$, es posible afirmar que este se comprende a partir dos grandes momentos: en el primero, se reconoce como tema central el eros-eros y se desarrolla mediante tres discursos. Un primer discurso, construido por Lisias y leído por Fedro, y los dos siguientes de autoría de Sócrates. En el primer discurso socrático, como se indicó, se siguió la estructura señalada por el retórico Lisias, secundando -Sócrates- la idea del amante indiferente; el segundo discurso, en cambio, es proyectado por Sócrates a manera de una retractación (palinodia) en honor a la verdad constituyente de la buena y bella retórica. Descrito en la Paideia de Jaeger, la estructura del diálogo se menciona de la siguiente manera:

\begin{abstract}
La llamada parte erótica, o sea la primera, comienza con la lectura y la crítica de un discurso de Lisias, a quien se presenta como el dirigente de la escuela retórica más influyente de Atenas, que en tiempo de Sócrates se hallaba en el apogeo de su prestigio. Platón le enfrenta sucesivamente dos discursos de Sócrates sobre el mismo tema, el valor del eros, para demostrar una de dos cosas; cómo, partiendo de las falsas premisas de Lisias sobre el eros, se puede tratar el mismo tema mejor que él lo hace o cómo se debe exponer este problema cuando se conoce lo que verdaderamente es. En la segunda parte, a tono con lo anterior, se empieza exponiendo de un modo más bien general los defectos de la retórica y de los sistemas retóricos imperantes en tiempo de Sócrates, para luego esclarecer los méritos de la dialéctica socrática como medio de una verdadera retórica (Jaeger, 2001: 984-985).
\end{abstract}

Para el segundo momento del diálogo, se presenta el tema de la retórica y del discurso verdadero en torno al amor y al alma, acompañado de la trama acerca de la conveniencia o no de escribir. De este modo, el texto alcanza su unidad y armonía, haciéndose 
consistente en virtud de la retórica verdadera como objeto de preocupación.

\section{El discurso bello y bueno}

A propósito de lo anterior, resulta pertinente, a la luz del diálogo que aquí se comenta, preguntarse ¿Cómo es posible, entonces, la bella y buena construcción del discurso? ¿Cuál es la manera para escribir bien? (258d) ¿Cuál es la causa por la que un discurso, hablado o escrito, es o no es bueno?

Todos estos cuestionamientos son en cierto modo resueltos, según Julián Marías en su introducción al texto del Fedro (1948), por el modus operandi esbozado por Platón en su intento por alcanzar la episteme. Con tal pretensión, Platón, en el Fedro y a través de Sócrates, hace una objeción contundente al discurso de Lisias -y al suyo propio- sobre el amor, señalando que en esos discursos no se ha discutido lo que es el tema en cuestión, e invitando de esta manera a:

(...) Tener claridad sobre el asunto del cual se delibera (ejemplo definir ¿qué es el amor? ¿En qué consiste? ¿Cuál es su fuerza?) Evitando así, incurrir fácilmente en errores. Sumado a esto, Platón reclama la importancia de la definición pues esta permite "1) tener el objeto a la vista; 2) ponernos de acuerdo. En el diálogo sofístico o retórico no existe este acuerdo, y puede ocurrir que no se hable de lo mismo. Pero si se parte de una definición y esta fuese el fin del discurso, la disertación entera sobraría (Marías, 1948: 91-92).

Siguiendo este orden de ideas, y como primera aproximación a modo de respuesta a los anteriores cuestionamientos, se reconoce la claridad como condición de posibilidad para los discursos bellos y buenos, claridad que solo es alcanzada en presencia de la verdad. Esto resulta contrario a lo manifestado previamente por Fedro a Sócrates, cuando afirma:

Fedro. - Fíjate, pues, en lo que oí sobre este asunto, querido Sócrates: que quien pretende ser orador, no necesita aprender qué es, de verdad, justo, sino lo que opine la gente que es la que va a juzgar; ni lo que es verdaderamente bueno o hermoso, sino sólo lo que lo parece. Pues es de las apariencias de donde viene la persuasión, y no de la verdad. (Platón, Diálogo III (Fedón, Banquete y Fedro), 1988: 373) $\left(260^{\mathrm{a}}\right)$.
Contra este tipo de enseñanzas se instala la propuesta filosófica y pedagógica de Platón. Como primera recomendación dada por Sócrates se encuentra que el discurso tenga como principio y punto de partida la verdad sobre aquello de lo que se habla, pues el pensamiento de quien habla deberá ser conocedor de esta verdad a fin de no abordar el tema desde presupuestos falaces y apenas aparentes. Esta argumentación -en Sócrates- estará acompañada de una serie de mitos y/o relatos que posibilitan, mediante imágenes, la contundencia argumentativa del filósofo. Así, para responder a los cuestionamientos señalados, Platón acude, por ejemplo, al mito de las cigarras $\mathrm{y}$ al don que pueden darle a los hombres $(259 \mathrm{c})$, pretendiendo que estos pasen su vida en la filosofía y honren su música.

Luego de lo señalado, Platón, a través de Sócrates, continúa examinando las causas por las cuales un discurso hablado o escrito es o no es bueno:

Sócrates. - y bien, examinemos lo que nos habíamos propuesto ahora, lo de la causa por la que un discurso hablado o escrito es o no es bueno.

Fedro. - De acuerdo.

Sócrates. - ¿No es necesario que, para que esté bien y hermosamente dicho lo que se dice, el pensamiento del que habla deberá ser conocedor de la verdad de aquello sobre lo que se va a hablar? (Platón, 1988:373) (259e).

Para dar claridad a ello, Platón -en la voz de Sócratesexpone la analogía de recomendar un asno como si fuese un caballo (260b), agregando luego una crítica al maestro de retórica que estudia las opiniones de la gente y las apariencias con el propósito de persuadir, ignorando la verdad que se construye en relación al objeto:

Sócrates. - Por consiguiente, cuando un maestro de retórica, que no sabe lo que es el bien ni el mal, y en una ciudad a la que le pasa lo mismo, la persuade no sobre la «sombra de un asno», elogiándola como si fuese un caballo, sino sobre lo malo como si fuera bueno, y habiendo estudiado las opiniones de la gente, la lleva a hacer el mal en lugar del bien, qué clases de frutos piensa que 
habría de cosechar la retórica de aquello que ha sembrado? $d$

Fedro. - No muy bueno, en verdad.

Sócrates. - En todo caso, buen amigo, ¿no habremos vituperado al arte de la palabra más rudamente de lo que conviene? Ella, tal vez, podría replicar: " ¿qué tonterías son ésas que estáis diciendo, admirables amigos? Yo no obligo a nadie que ignora la verdad a aprender a hablar, sino que, si para algo vale mi consejo, yo diría que la adquiera antes y que, después, se las entienda conmigo. Únicamente quisiera insistir en que, sin mí, el que conoce las cosas no por ello será más diestro en el arte de persuadir» (Platón, 1988:374-375).

Trataba con ello Platón, indudablemente, de establecer el ejemplo de una nueva retórica sobre bases científicas, que superara el yugo de la retórica afincada en la persuasión, en la apariencia y la mera opinión, entendida esta -en su sentido epistemológico- como lo opuesto a la episteme, propuesta que, al interior del Fedro, da cuenta de una urgencia por depurar las proposiciones y argumentos del orador, en este caso, respecto al tema del amor y del alma, como lo señala Luis Gil (1983) en sus comentarios al texto del Fedro:

¿Qué otra cosa es la retórica científica sino filosofía en su más puro sentido, un tratar de llegar al conocimiento de las verdaderas realidades de las cosas para infundir después en las almas de los componentes del auditorio la persuasión y la virtud? El tema del amor queda, pues, plenamente justificado dentro de la economía general del diálogo. Y lo mismo ha de decirse del tema del alma. (Gil, 1983: 248).

Platón muestra así, en su diálogo a través del tema del amor y del alma, que un discurso, sea oral o escrito, para ser bello y bueno no puede desconocer la verdad del objeto del discurso pues, de ser así, sería en sí mismo despreciable, propio de la retórica de su época, como se confirma en la voz de Sócrates: "Luego el arte de las palabras, compañero, que ofrezca el que ignora la verdad, y vaya siempre a la caza de opiniones, parece que tiene que ser algo ridículo y burdo" (262 c). El discurso así constituido quedaría entonces condenado al fracaso por su ignorancia de la verdad, al preferir -en lugar de la alétheia-alhqei $\alpha$ - a la doxa-dox $\alpha$ (estado de opinión carente de suficiencia), y caminando, por tal razón, por el sendero de la ignorancia filosófica, que consiste en no saber lo que se debe saber cuándo se habla o escribe. Pero además, Platón enlaza a este concepto el de la techné:

[...] Niega que la retórica sea un arte en el sentido estricto de la palabra y la considera como una simple rutina, carente de toda base material. Sólo puede convertirse en un verdadero arte a condición de que se apoye en el conocimiento de la verdad. (Jaeger, 2001: 989).

Aclarado el asunto de la verdad que debe subyacer en el discurso para ser considerado bello y bueno, se sigue la segunda recomendación de Platón para estos efectos, la cual, consiste en el reconocimiento y la comprensión de las diferencias y semejanzas entre las cosas como un método de clasificación de las mismas. Resalta Platón la importancia de ir analizando poco a poco, paso a paso cada uno de los componentes relativos al argumento, evitando incurrir en la comparación de todo con todo y de operar de manera única y exclusiva con los recursos de la semejanza, como es común en la retórica.

Sócrates. - Ya verás cómo se nos hará evidente, si buscamos en esa dirección. ¿Se da el engaño en las cosas que difieren mucho o en las que difieren poco?

Fedro. - En las que poco.

Sócrates. - Es cierto, pues, que si caminas paso a paso, ocultarás mejor que has ido a parar a lo contrario, que si vas a grandes saltos.

Fedro. - ¡Cómo no!

Sócrates. - Luego el que pretende engañar a otro y no ser engañado, conviene que sepa distinguir, con la mayor precisión, la semejanza o desemejanza de las cosas

Fedro. - Seguramente que es necesario.

Sócrates. - ¿Y será realmente capaz, cuando ignora la verdad de cada una, de descubrir en otras cosas la semejanza, grande o pequeña, de lo que desconoce?

$b$ Fedro. - Imposible.

Sócrates. - Así pues, cuando alguien tiene 
opiniones opuestas a los hechos y se engaña, es claro que ese engaño se ha deslizado en él por el cauce de ciertas semejanzas.

Fedro. - En efecto, así es.

Sócrates. - ¿Es posible, por consiguiente, ser maestro en el arte de cambiar poco a poco, pasando en cada caso de una realidad a su contraria por medio de la semejanza, o evitar uno mismo esto, sin haber llegado a conocer lo que es cada una de las cosas que existen?

Fedro. - No, en manera alguna. (Platón, 1988: 378).

Así, en la argumentación citada se justifica lo que implica reconocer la palabra como un auténtico arte, alimentado siempre por la verdad de lo dicho como condición para lo bello y lo bueno, alejado de las meras opiniones (dox $\alpha$-doxa) que lo harían ver como ridículo y burdo.

Finalmente, se infiere del diálogo del Fedro, como tercera consideración, que el discurso oral y el escrito deben estar constituidos como un organismo vivo, que consta de cabeza y extremidades que se vinculan recíprocamente de tal forma que no sea por consiguiente "Acéfalo, ni le falten los pies, sino que tenga medio y extremos, y que al escribirlo se combinen las partes entre sí y con el todo" (264c) (Platón, 1988: 291), estando en consecuencia ordenado. Tal situación la ratifica Werner Jaeger en la Paideia cuando señala que todo discurso:

Debe tener, al igual que un ser vivo, un cuerpo orgánico. No debe carecer de cabeza ni de pies, sino tener un verdadero tronco y verdaderas extremidades, y todos estos miembros han de guardar una relación adecuada entre sí y con el todo. Desde este punto de vista, el discurso de Lisias constituye un producto totalmente defectuoso. Platón descubre aquí una visión profunda de lo que debe ser la composición literaria. (Jaeger, 2001: 990).

Esta tercera recomendación de Platón se conjuga con la anterior, en la que se sugería que el orador estuviese en la capacidad de distinguir las diferencias y semejanzas de las cosas sobre las que habla, pudiendo clasificarlas y debiendo - para ello- conocerlas en su verdad, como lo afirma Mary McCoy:
Socrates then describes a positive form of rhetoric that uses a method of collection and division (q.v. Method) that draws together what one wishes to explain into a common category, and then divides it again according to its 'natural joints' ( Phdr . 265d-e). Ideally, a speaker's discourse should be well ordered, like a 'living being' (264c) (McCoy, 2012: 242).

Ahora bien, para alcanzar verdaderamente el Bien y la Belleza a través del discurso, de la forma como se ha venido exponiendo a lo largo del presente artículo, es necesario que además de seguir todas estas recomendaciones, el orador/escritor estudie, conozca y comprenda la naturaleza del alma de quien lo escucha, de quien lo lee, pues solo haciendo este reconocimiento sabrá -este orador o este escritorqué clase de discurso debe dirigir con el fin de llegar al alma de su interlocutor (o lector), así lo asevera Román Cámara:

Para hacer realidad la idea de un arte de los discursos, los oradores habrán de estudiar la naturaleza del alma, ver si es simple o compuesta, las partes que la constituyen y qué es lo que puede hacer o sufrir. Habrán de clasificar los géneros de discursos y de almas, para saber qué clase de almas se dejan persuadir por efecto de qué clase de discursos. Los oradores necesitarán también observar en acción a los demás, relacionar su éxito con la teoría y aprender a aplicar ellos mismos esta teoría. (Román Cámara, 2008:196).

Este reconocimiento del Otro $-y$ de lo Otro-, que determina la estructura y el contenido del discurso mismo, que selecciona las palabras adecuadas para lograr el efecto con él pretendido, que abre la posibilidad de comprender al otro para dirigirlo desde su particularidad-hasta el mensaje del discurso, no es otra cosa que el pluralismo que hoy reclaman los escenarios académicos, políticos -e incluso jurídicos- contemporáneos. Así como se había resaltado antes, en otros espacios distintos en los que se apelaba al mismo principio de reconocimiento de la diferencia y la diversidad, el pluralismo deviene en un reto y en un compromiso necesario dentro de todos aquellos contextos que supongan una pretensión educadora, ya sea a nivel académico, político o ciudadano, según lo han puesto de presente distintos autores. Así, desde el punto de vista jurídico 
y ciudadano, Rengifo-Castañeda, Wong Jaramillo \& Posada, expusieron lo siguiente:

El Pluralismo Jurídico en tanto asume que existen contextos distintos, grupos de creencias y valores, no necesariamente niega la objetividad. Las reglas jurídicas al relacionarse con contextos desiguales, sugieren interpretaciones distintas. Lo irracional sería que en un mismo contexto, un mismo sistema de creencias generara contradictorias interpretaciones [...].Así, el Pluralismo Jurídico al asumir la condición variable de la cultura humana, recoge un rasgo objetivo de la humanidad: su diversidad. (Rengifo-Castañeda, Wong Jaramillo \& Posada, 2013: 37).

En el plano de la Academia, igualmente vinculado con la ciudadanía, Vélez Medina expuso:

[...] la universidad del presente ha empezado a convivir con la pluralidad de contenidos, ideas, métodos y verdades. No toda su comunidad académica actual se deja convencer del dogmatismo, incluso empieza a circular la idea que el radicalismo de izquierda tampoco es la solución: "si llegáramos a reconocer la profundidad de nuestras diferencias, quizá podríamos optar por la idea plural de universidad que queremos reformar"(Hoyos, 1998). La universidad post-metafísica es aquella que no se niega a la confrontación radical de sus preceptos, pensamientos o formas de vida, pues entiende que casi todos ellos son a la postre, incompatibles y complementarios. Esta academia que empieza a surgir (aún sin reconocerse), tiene la misión ya no de buscar la verdad, sino de acoger diversas concepciones del bien, propiciar escenarios de interpretación del mundo y despertar la capacidad de tejer relaciones sociales, geo-políticas, económicas y científicas frente a los acontecimientos del mundo (Vélez Medina, 2014: 252).

Así, y siguiendo la disertación socrática, es el reconocimiento de ese pluralismo lo que determina, finalmente, si el discurso habrá alcanzado o no la belleza y la perfección en el decir, en el enseñar o en el escribir:

Puesto que el poder de las palabras se encuentra en que son capaces de guiar las almas, el que pretenda ser retórico es necesario que sepa, del alma, las formas que tiene, pues tantas y tantas hay, y de tales especies, que de ahí viene el que unos sean de una manera y otros de otra [...] Conviene, además, habiendo reflexionado suficientemente sobre todo esto, fijarse en qué pasa en los casos concretos y cómo obran [...], cuando sea capaz de decir quién es persuadido y por qué clase de discursos, y esté en condiciones de darse cuenta de que tiene delante a alguien así, y explicarse a sí mismo que "éste es el hombre y ésta es la naturaleza sobre la que, en otro tiempo, trataron los discursos y que ahora está en persona ante mí, y a quien hay que dirigir y de tal manera los discursos, para persuadirle de tal y tal cosa'. Cuando esté, pues, en posesión de todo esto , y sabiendo de la oportunidad de decir algo en tal momento, o de callárselo, del hablar breve o del provocar lástima, y de las ampulosidades y de tantas cuantas formas de discurso aprendiera, y sabiendo en qué momentos conviene o no conviene aplicarlos, entonces es cuando ha llegado a la belleza y perfección en la posesión del arte, mas no antes (Platón, 1988: 396-397).

\section{Conclusiones}

El diálogo del Fedro da cuenta de la actitud de Platón frente a la retórica inferida desde Lisias, y lo que ha de constituirse como los presupuestos para una nueva retórica con las bases científicas necesarias en su Paideia, pues el objetivo perseguido en el Fedro es la formación del espíritu tanto del orador como del escritor, contrastando efectivamente la educación retórica con la educación filosófica, según lo aclara Jaeger en sus comentarios al Fedro:

La verdadera escritura es la que se graba en el alma del que aprende, pues ésta sí tiene la fuerza necesaria para acudir en su propio auxilio. El único provecho de lo escrito, de lo estampado con tinta, es que recuerda lo que ya se sabe. Mientras que la retórica de la época se orienta cada vez más hacia el arte de la escritura y el "discurso gráfico", Platón funda la superioridad educativa de la dialéctica filosófica sobre ella en el hecho de que se dirige directamente al espíritu y lo forma (Jaeger, 2001: 997).

Por esto, a decir de Julián Marías, la filosofía en Platón se distingue entre

Una adquisición (kthsic) de los conocimientos, un uso (crhsic) de ellos y un hábito (ezic) que crean 
en el alma, y que es el que hace propiamente que se use bien. De ahí la mayor confianza en el diálogo que en el escrito (Marías, 1948: 94).

Todo lo dicho es una clara propuesta de orden pedagógico que configura el alma tanto del escritor como del orador, en correspondencia con el discurso bello y bueno, y afincado tanto en la verdad como en su estructura. Se trata, en definitiva, del escrito que se graba en el alma de quien aprende y lo forma, siendo esta la esencia de la verdadera educación que transita entre una retórica verdadera y una constante dialéctica, esta última permite alcanzar la claridad y la coherencia entre lo uno y lo múltiple, como base para estructurar el pensamiento en torno a una bella y buena construcción del discurso. Tal vez sea esta fabricación, así sugerida por Platón, que parte de la verdad que proporciona claridad y se extiende hacia las partes que componen el argumento o el discurso, lo que podría permitir, además, recuperar la credibilidad en el orador que se desenvuelve en los escenarios educativos, políticos y jurídicos actuales, y con ello recuperar, al mismo tiempo, la belleza y la bondad en el ejercicio político y académico.

\section{Referencias bibliográficas}

Garcia, C. P. (2007). La locura Divina de Eros en el Fedro de Platón. Cauriensia , 93-119.

Gonzalez, F., Nails, D., \& Tarrant, H. (2012). The Continuum Companion to Plato. London: Gerald A. Press.

Görgemanns, H. (2010). Platón. Una Introducción. Chile: Instituto de Estudios de la Sociedad, IES.

Guthrie, K. (1990). Historia De La Filosofia Griega IV Platón El Hombre y sus Diálogos: Primera Época. Madrid: Gredos.

Jaeger, W. (2001). Paideia: los ideales de la cultura griega. México: Fondo de Cultura Económica.

Koyre, A. (1966). Introducción a la Lectura de Platón. Madrid: Alianza.
McCoy, M. (2012). Rhetoric (Retorikê); Topics and Themes Treated in the Dialogues. En G. A. (Ed.), The Contnuum Companion to Plato (pág. 377). London: Continuum International Publishing Group.

Nussbaum, M. C. (2004). La Fragilidad del Bien. Madrid: Machado Libros.

Platón. (1948). Fedro. Buenos Aires: Revista de Occidente.

(1983). El Banquete, Fedón, Fedro. Madrid: Orbis.

------. (1988). Diálogo III (Fedón, Banquete y Fedro). Madrid: Gredos.

Rengifo-Castañeda, C.-A., Wong Jaramillo, E., \& Posada, J. (2013). Pluralismo Jurídico: Implicaciones Epistemológicas. Inciso , 27-40.

Román Cámara, B. (2008). La Concepción de la Retórica en el Fedro de Platón. En S. d. Valencià, XVII Congrés Valencià de Filosofia (pág. 436). Valencia: Universitat de Valencià.

Szaif, J. (2007). Doxa and Epistêmê as Modes of Acquaintance in Republic V. Les Etudes Platoniciennes, vol. IV, Paris: Les Belles .

Vélez Medina, B. (2014). A propósito de las reformas a la educación y la necesidad de una reivindicación de la pluralidad. Sophia , 10 (2), 246-252. 